\title{
Avaliação de testes de hipóteses para identificação de proporção áurea
}

\author{
Mariana M. Gonçalves Santos* Luiz Alberto Beijo \\ Instituto de Ciências Exatas, Universidade Federal de Alfenas - UNIFAL-MG \\ 37130-000, Alfenas - MG \\ e-mail:marireigo@hotmail.com, luiz.beijo@unifal-mg.edu.br,
}

\section{RESUMO}

A proporção áurea tem sido objeto de interesse de diversos estudiosos das mais diferentes áreas. Sua primeira definição formalizada foi dada por volta de 300 a. C., por Euclides de Alexandria: um segmento de reta é dividido em média e extrema razão (em dois outros segmentos) se a razão entre o maior e menor for igual à razão entre a soma de ambos e o maior. O número irracional obtido dessas razões, aproximadamente 1,618 , é chamado de proporção áurea, também conhecido como número de ouro, ou razão divina e é denotado por $\Phi$ [3].

A proporção áurea pode ser encontrada não só em inúmeros objetos produzidos pelo homem como também em fenômenos naturais. Frequentemente associada à beleza, à harmonia, ao equilíbrio, atualmente pesquisas têm indicado que propriedades como a rigidez, estabilidade e eficiência estão relacionadas às estruturas que apresentam a proporção áurea [2]. Em literatura nã existe um teste consagrado para a identificação de proporção áurea, e diversas metodologias têm sido utilizadas com este objetivo. Entre elas pode-se destacar as metodologias baseadas: no teste t de Student, em métodos não paramétricos, na análise de variância, e até, em critérios subjetivos.

O objetivo desse trabalho foi identificar, via simulação de dados, um teste que tenha melhor desempenho para a caracterização de proporção áurea. Foram avaliadas a taxa de erro tipo I e poder dos testes, para diferentes condições variabilidades e tamanhos de amostra.

Foram simulados, usando o programa R (R DEVELOPMENT CORE TEAM)[5], valores para segmentos $a_{i}$ e $b_{i}$, com $b_{i}>a_{i}$ em dois diferentes casos. No caso I, para valiar a taxa de erro tipo I, $b_{i}$ foi gerado a partir de $a_{i}$ de modo que estivessem em proporção áurea. No caso II, para valiar o poder dos testes, uma vez que $b_{i}$ foi gerado a partir de $a_{i}$ multiplicado por outra constante, $\Phi+0,4$, ou seja, da razão $R=\frac{a}{b}$ não se apresenta em proporção áurea.

A avaliação do erro tipo I foi feita observando-se a porcentagem de vezes que a hipótese nula $\left(H_{0}\right)$ foi rejeitada[1], no caso I. Utilizou-se o teste binomial exato para avaliar se a taxa de erro tipo I era estatisticamente igual ao nível nominal testado (5\%). Para a determinação e comparação do poder dos testes foram observadas a porcentagem de rejeições da hipótese nula[1], no caso II.

Para ambas as situações, foram simulados 5000 valores e retirados diferentes tamanhos de amostra: $2,3,4,5,6,7,8,9,10,15,20,25,30,50$ e 100 . O valor considerado para $\Phi$ foi 1,618 e o nível de significância adotado para os testes foi de $5 \%$. Quanto à variabilidade, o desvio padrão relativo de $a_{i}$ e $b_{i}$ foram iguais a $5 \%, 10 \%, 15 \%$ e $20 \%$ de suas médias.

Foram avaliados três testes, denominados TD, TME e TR.

O teste TD, consiste na aplicação do teste t de Student na definição de proporção áurea, dada por Euclides. Sendo $a_{i}$ e $b_{i}$ segmentos, com $b_{i}>a_{i}$ e $\Delta_{i}$ a diferença entre as duas razões da definição, então $\Delta_{i}=\left(\frac{b_{i}}{a_{i}}-\frac{a_{i}+b_{i}}{b_{i}}\right)$. Foi testada a hipótese se a média das diferenças é nula $\left(H_{0}: \mu_{\Delta}=0\right)$.

No teste TME foi utilizado o teste t de Student emparelhado. Se $a_{i}$ e $b_{i}$ estão em proporção áurea, então $b_{i}=\Phi \times a_{i}$, com $\left(b_{i}>a_{i}\right)$. Dessa forma testou-se a hipótese de que a média dessas diferenças $\left(D_{i}=b_{i}-\Phi \times a_{i}\right)$ é igual a zero $\left(H_{0}: \mu_{D}=0\right)$.

\footnotetext{
* Mestranda bolsista CAPES - Agradecimento à FAPEMIG pelo apoio financeiro
} 
No teste TR foi utilizado o teste t de Student e verificou-se a hipótese de que a média da razão entre os segmentos $R=\frac{a}{b}$ é igual a $\Phi\left(H_{0}: \mu_{R}=\Phi\right)$.

Observou-se que o aumento do coeficientes de variação tanto do menor segmento $\left(c v_{a}\right)$ quanto do maior $\left(c v_{b}\right)$, tiveram efeito nas taxas de erro tipo I e no poder dos testes avaliados. Sendo assim, é imprescindível que o pesquisador tenha conhecimento da variabilidade dos segmentos para escolha do teste adequado na identificação de proporção áurea.

ONO et al [4] utilizaram o teste TR para análise da proporção áurea em 200 indivíduos por meio de radiografias e não levaram em consideração o coeficiente de variação de cada fator da razão, podendo ter cometido erros em suas conclusões.

Para os casos em que o coeficiente de variação dos dois segmentos são pequenos (ambos $5 \%$ ) ou próximos $\left(c v_{a}=5 \%\right.$ com $\left.c v_{b}=10 \%\right)$ os testes TD e TME apresentaram bom desempenho no controle das taxas de erro tipo I e alto poder $(>95 \%)$ para os tamanhos de amostra acima de 7. O teste TR, para amostras acima de 10, não controla a taxa de erro tipo I, embora apresente alto poder ( $>95 \%$ ), porém para amostras menores controla taxa de erro tipo I, mas apresenta baixo poder.

Em outros casos de proximidade dos coeficientes de variação dos dois segmentos ou que o coeficiente de variação de um dos segmentos é pequeno $c v=5 \%$, os testes TD e TME apresentam resultados iguais e o teste TR não controla a taxa de erro tipo I.

Quando as variabilidades dos dois segmentos são altas, tamanhos de amostra maiores são necessários para que os testes tenham um alto poder. Deve-se considerar as taxas de erro tipo I, que na maioria das vezes. aumenta com o aumento do tamanho de amostra para os testes TR e TD.

O teste TME controlou as taxas de erro tipo I para todos os tamanhos de amostras e em todas variabilidades analisadas, porém para se ter bom desempenho em poder, é necessário tamanhos de amostra maiores quando a variabilidade dos dois segmentos aumenta.

O tamanho de amostra recomendado para a realização de um teste para identificação de proporção áurea depende da variabilidade de cada segmento.

O teste t emparelhado (TME), verificando a hipótese de que a média das diferenças $\left(D_{i}\right)$ é igual a zero, controlou o erro tipo I e apresentou alto desempenho quanto ao poder para amostras relativamente pequenas.

O teste $t$ de Student (TD) com base na hipótese $\left(H_{0}: \mu_{D}=0\right)$ é recomendado apenas em situações que o cv dos dois segmentos é pequeno.

O teste $\mathrm{t}$ de Student (TR)com base na hipótese de que a média da razão entre os segmentos $R=\frac{a}{b}$ é igual a $\Phi$ não é recomendado para a identificação de proporção áurea.

Palavras-chave: Número de ouro, tamanho de amostra, erro tipo I, poder

\section{Referências}

[1] BUSSAB, W. O., MORETTIN, P. A. Estatística Básica. 5. ed. São Paulo: Saraiva, 2002.

[2] GIL, C. T. L. A. Proporção áurea craniofacial. São Paulo: Ed. Santos, 2001.

[3] LÍVIO, M. Razão Áurea: a história de Fi, um número surpreendente. Rio de Janeiro: Record, 2008. $333 \mathrm{p}$.

[4] ONO, E., PORTO; C. O. T. W.; MEDICI FILHO, E.; MORAES, L. C.; MORAES, M. E. L.; CASTILHO, J. C. M. Análise da proporção áurea em indivíduos dolico, braqui e mesofaciais, por meio de radiografias cefalométricas laterais. Revista Odonto Ciência. 2007, v. 22, p. 154-159

[5] R DEVELOPMENT CORE TEAM. An Introduction to R: Version: 3.01. 2013. Disponível em: http://www.r-project.org. Acesso em: 10 de agosto de 2013. 